\title{
PENDIDIKAN KESEHATAN TERHADAP PENGETAHUAN KESIAPSIAGAAN MASYARAKAT DALAM MENGHADAPI BENCANA BANJIR DI DAERAH PETEMON SURABAYA
}

\author{
Wijar Prasetyo ${ }^{1,}$ Hendro Djoko Tjahjono ${ }^{2}$ \\ ${ }^{1,2}$ STIKes William Booth Surabaya Jl.Cimanuk No. 20 Surabaya. \\ Email :wijar85@gmail.com
}

\begin{abstract}
ABSTRAK
Banjir merupakan aliran air di permukaan tanah yang relatif tinggi dan tidak dapat ditampung oleh saluran drainase sehingga melimpah serta merugikan manusia karena jumlahnya melebihi normal. Daerah petemon merupakan dataran rendah sehingga saluran air tidak dapat menampung volume air yang menyebabkan air meluap kedataran. Untuk meningkatkan pengetahuan dapat dilakukan dengan promosi pendidikan kesehatan dengan memberikan penyuluhan terhadap warga agar bisa menambah wawasan, pengetahuan dan kesadaran masyarakat terkait bencana banjir. Penelitian ini bertujuan untuk mengetahui Pengaruh Tingkat Pengetahuan Terhadap Kesiapsiagaan Masyarakat Dalam Menghadapi Banjir Di Petemon Surabaya. Desaign penelitian ini Pre Eksperimen One Groups Pretest-Posttest yang bertujuan untuk menganalisa warga masyarakat yang mengalami tingkat pengetahuan sebelum dan sesudah dilakukan dengan menyebarankan kuesioner berisi pertanyaan seputar bencana banjir dan tingkat pengetahuan. Populasi penelitian ini adalah 50 masyarakat dengan sampel 44 responden dengan teknik pengambilan Purposive Sampling. Pengumpulan data menggunakan kuesioner sebelum dan sesudah diberikan kuesioner dianalisis menggunakan uji statistic Wilcoxon dengan tingkat signifikasi $\alpha<0,05$. Hasil yang didapatkan yaitu $\mathrm{P}=0.038$, menunjukkan terhadap pengaruh antara tingkat pengetahuan terhadap masyarakat di Petemon Surabaya. Berdasarkan hasil analisa data tersebut dapat disimpulkan bahwa tingkat pengetahuan berpengaruh pada masyarakat sehingga meningkatkan perilaku kesiapsigaan masyarakat, memahami dan menerapkan isi atau informasi yang diberikan saat dilakukan pendidikan kesehatan.
\end{abstract}

Kata Kunci : Tingkat Pengetahuan, Kesiapsiagaan masyarakat.

\begin{abstract}
Flooding is a relatively high flow of water on the ground surface and cannot be accommodated by drainage channels so that it is abundant and detrimental to humans because the amount exceeds normal. The petemon area is a lowland so that the waterways cannot accommodate the volume of water which causes the water to overflow to the flat. To increase knowledge, it can be done by promoting health education by providing counseling to residents so that they can add insight, knowledge and public awareness regarding flood disasters. The objective of research is to determine the effect of knowledge level on community preparedness in facing floods in Petemon Surabaya. The design of this research is Pre-Experiment One Groups PretestPosttest which aims to analyze community members who experience the level of knowledge before and after it is carried out by distributing questionnaires containing questions about flood disaster and level of knowledge. The population of this study was 50 people with a sample of 44 respondents using purposive sampling technique. Data
\end{abstract}


collection used a questionnaire before and after being given the questionnaire was analyzed using the Wilcoxon statistical test with a significance level of $<0.05$. The results obtained are $\mathrm{P}=0.038$, indicating the influence of the level of knowledge on the community in Petemon Surabaya. Based on the the data analysis, it can be concluded which the level of knowledge affects the community so that it increases the behavior of community preparedness, understands and applies the content or information provided during health education.

Keywords : The level of community, preparedness knowledge.

\section{PENDAHULUAN}

Berbagai wilayah di Indonesia rawan terhadap berbagai jenis bencana, termasuk bencana alam. Jenis Bencana alam di Indonesia dapat diklasifikakan menjadi dua yaitu bencana yang diakibatkan oleh alam dan bencana yang disebabkan oleh manusia. Bencana yang berasal dari alam meliputi gunung meletus dan tsunami sedangkan bencana yang diakibatkan campur tangan manusia adalah banjir, kebakaran dan polusi maka (Marfai, 2014). Manusia melakukan perubahan system ekologi yang telah ada sehingga terjadi bencana banjir. Banjir merupakan salah satu jenis bencana yang kerap terjadi setiap tahun di Indonesia dan memiliki dampak pada hidup manusia dan lingkungan. Bencana banjir dapat diartikan sebagai aliran air di permukaan tanah yang tinggi dan tidak dapat ditampung oleh saluran drainase sehingga jumlah airnya melimpah dan menimbulkan genangan serta mengakibatkan kerugian pada manusia (Rahayu, et al., 2009). Sebagian besar wilayah di Indonesia berpotensi terjadi banjir. Banjir dapat dipicu oleh karena kepadatan penduduk. Jawa Timur merupakan satu dari provinsi yang ada di Pulau Jawa yang sering dilanda banjir (Rosa, et al., 2013) terutama bagi para penduduk yang tinggal di wilayah perkotaan negara-negara yang berkembang termasuk kota Surabaya.
Hal ini merupakan beberapa wilayah bencana banjir. Disamping itu permasalahannya lainnya muncul oleh karena pada saat banjir datang alat dan prasarana sanitasi kurang dapat berfungsi maksimal. Selain itu juga ketika banjir melanda, masyarakat tidak mempedulikan pengelolaan sampah. Sehingga ketika bencana banjir berlangsung masyarakat membuang sampah sembarangan (hasil observasi peneliti 2017). Masalah pada didaerah Petemon terdapat memiliki dataran rendah dari kerendaha dan saluran air tidak dapat menampung volume air sehingga air meluap kedataran. Untuk meningkatkan pengetahuan serta sikap dapat dilakukan dengan promosi pendidikan kesehatan yang salah satunya dapat dilakukan dengan memberikan penyuluhan pendidikan kesehatan terhadap warga agar bisa menambah wawasan, pengetahuan dan kesadaran masyarakat terkait bencana banjir. Pendidikan kesehatan tersebut berisi tentang bagaimana cara kita untuk menyelamatkan diri dan keluarga pada saat banjir dating dan cara menyelamatkan barang berharga agar tidak terendam banjir dan mematikan listrik jika banjir sudah memasuki rumah dan kesiapsiagaan warga sebelum mrnghadapi banjir yang akan datang.

Indonesia adalah negara yang rawan bencana, mengingat kondisi 
geografi dan geologi indonesia yang terletak pada pertemuan tiga eurasia, australia, dan pasifik (Ruswandi,2014). Banjir merupakan satu dari bencana yang besar di Indonesia dimana tahun 2013 bohorok sumatera utara, korban kurang lebih 300 orang, lebih dari 400 rumah hancur, turun hujan selama 2-5 jam (Adi, 2014). Data Badan Nasional Penanggulangan Bencana (BNPB) diperoleh 1.538 kejadian bencana banjir di Indonesia pada tahun 2019 yang dihitung mulai 1 Januari sampai 30 April. Informasi dari Kepala Pelaksana BPBD Provinsi Jawa Timur menyampaikan bahwa di Jawa Timur terdaapt 38 kabupaten atau kota yang mengalami banjir dan salah satunya adalah Surabaya. Luas wilayah Surabaya meliputi daratan dengan luas $350,54 \mathrm{~km}^{2}$ dan lautan seluas $190,39 \mathrm{~km}^{2}$ dengan penduduknya berjumlah 2.941.981 jiwa (2019). Banjir merupakan salah satu kejadian bencana yang sering terjadi di Kota Surabaya. Diantarnya di kawasan Kelurahan Petemon Kecamatan Sawahan Kota Surabaya memiliki letak dengan daerah aliran sungai (DAS) yang bernama Kali Gerges. Dimana kali tersebut merupakan saluran dari DAS yang menyebabkan Kelurahan Petemon mengalami banjir, Karena kondisi di Daerah Petemon tersebut merupakan dataran rendah. Banjir tersebut terjadi oleh karena hujan terus menerus dan saluran air tidak dapat menampung volume air dan air meluap kedataran. Maka di daerah terjadi banjir diperlukan suatu program pencegahan atau pengelolaan yang tepat terhadap bencana banjir seperti tindakan mitigasi bencana banjir.

Banjir dapat terjadi oleh karena curah hujan yang tinggi tanpa adanya saluran pembuangan saluran pembuangan air sehingga merendam suatu wilayah. Penyebab utama yang mengakibatkan bencana banjir adalah kurangnya pemahaman masyarakat tentang bahaya banjir, sikap atau perilaku yang mendorong terjadinya bahaya banjir, kurangnya informasi tentang peringatan dini banjir termasuk upaya untuk menghadapi bencana, kerugian akibat banjir meliputi dan kerusakan bangunan rumah tinggal, fasilitas umum, serta infrastruktur yang lain. (Gumilar, 2013). Penyebab bencana banjir disebabkan oleh tingginya intensitas curah hujan tantangan serius untuk pembangunan dan kehidupan manusia, terutama bagi para penduduk yang menempati wilayah perkotaan kondisi ini diperburuk dengan lingkungan yang kotor akibat terjadinya banjir. Dampak banjir dapat menyebabkan penyakit yang menular seperti penyakit ISPA, diare, malaria, dan demam berdarah, macetnya kegiatan ekonomi warga, jalan berlubang bahkan hingga trauma yang dialami oleh warga masyarakat. Dampak lain yang cukup dirasakan adalah timbulnya kemacetan lalu lintas dan penurunan kesehatan masyarakat akibat pemukiman terserang wabah penyakit (Rahayu et al., 2014).

Untuk menanggulangi masalah banjir perlu dilakukan suatu pendidikan edukasi berupa pengetahuan, pemahaman, kesiapsiagaan dan keterampilan untuk mencegah, mendeteksi, dan besiap lebih dini untuk setiap macam bencana khususnya di daerah-daerah rawan bencana. Dan merupakan suatu keharusan bagi manusia untuk peka terhadap berbagai kemungkinan bencana yang dapat terjadi di sekitar tempat tinggalnya. Pelaksanaan penanggulangan bencana diperlukan upaya terpadu dari partisipasi masyarakat dan pemerintah dengan semaksimal mungkin memberdayakan potensi dan sumberdaya setempat. Penanggulangan 
bencana merupakan tanggung jawab bersama antara pemerintah, masyarakat yang bertumpu pada kemandirian dan keswadayaan masyarakat. Penanggulangan bencana difokuskan kepada tahap sebelum terjadinya bencana, yang meliputi kegiatan pencegahan, penjinakan, kesiapsiagaan, penyelamatan untuk memperkecil dan mengurangi dampak yang ditimbulkan oleh bencana (KEP. MENDAGRI No. 131 Tahun 2003).

Menurut Undang Undang Nomor 24 tahun 2007 tentang Penanggulangan Bencana, kesiapsiagaan merupakan serangkaian kegiatan yang dilakukan untuk mengantisipasi bencana melalui pengorganisasian. Diharapkan dengan melakukan persiapan kesiapsiagaan yang tepat dan cepat dapat meminimalisir jumlah korban dan kerus akan. Kesiapsiagaan merupakan syarat wajib bagi pengurangan resiko bencana. Kesiapsiagaan terhadap berbagai fenomena bencana dapat diperoleh dari pendidikan informal. Pendidikan informal dilakukan oleh keluarga dan lingkungan berbentuk kegiatan belajar secara mandiri. Pembelajaran tentang fenomena bencana dapat diperoleh melalui pengalaman, media cetak, penyuluhan. Pembelajaran tersebut dapat membentuk persepsi individu mengenai berbagai objek atau fenomena di sekitarnya.

\section{METODE}

Rancangan penelitian adalah sesuatu yang sangat penting dalam penelitian, memungkinkan pengontrolan maksimal beberapa faktor yang dapat mempengaruhi akurasi suatu hasil (Nursalam, 2016). Desain penelitian yang digunakan adalah pra experimental (one grup pre-post design) dengan variabel independent yaitu pendidikan kesehatan menggunakan leaflet dan variable dependent yaitu pengetahuan tentang kesiapsiagaan bencana..

Populasi penelitian merupakan seluruh warga RT 008 dan RT 009 Petemon Surabaya sebanyak 50 orang dengan besar sampel yang digunakan sebanyak 44 yang dipilih dengan teknik pengambilan sampel purposive sampling.

Instrumen yang digunakan dalam pengambilan data penelitian menggunakan kuisioner dan setelah data dikumpulkan dilakukan uji Wilcoxon untuk mengetahui pengaruh Pendidikan Kesehatan terhadap Kesiapsiagan Masyarakat dalam Menghadapi Bencana Banjir.

Prosedur pengambilan data dilakukan dengan cara sebelum diberikan Leaflet diberikan pretest. Kemudian setelah pendidikan kesehatan dengan media leaflet diberikan post test untuk mengetahui kefektifan pendidikan kesehatan yang diberikan.

\section{HASIL}

Tingkat pengetahuan tentang kesiapsiagaan bencana banjir sebelum diberikan pendidikan

Berdasarkan tabel 1 menunjukkan bawah responden sebelum diberikan penyuluhan memiliki tingkat pengetahuan baik sebanyak 36 orang $(87,8 \%)$, pengetahuan kurang sebanyak 3 orang $(7,3 \%)$ dan pengetahuan cukup sebanyak 2 orang $(4,9 \%)$.

Tingkat pengetahuan tentang kesiapsiagaan bencana banjir setelah diberikan pendidikan pendidikan kesehatan dalam mengahadapi bencana banjir 
Tabel 1 Tingkat pengetahuan tentang kesiapsiagaan bencana banjir sebelum diberikan pendidikan

\begin{tabular}{ccc}
\hline Kategori & Frequency & $\begin{array}{c}\text { Percent } \\
(\boldsymbol{\%})\end{array}$ \\
\hline Kurang & 3 & 7.3 \\
\hline Cukup & 2 & 4.9 \\
\hline Baik & 36 & 87.8 \\
\hline Total & $\mathbf{4 1}$ & $\mathbf{1 0 0 . 0}$ \\
& &
\end{tabular}

Tabel 2 Tingkat pengetahuan tentang kesiapsiagaan bencana banjir setelah diberikan pendidikan penyuluhan

\begin{tabular}{ccc}
\hline Kategori & Frequency & $\begin{array}{c}\text { Percent } \\
(\boldsymbol{\%})\end{array}$ \\
\hline Kurang & 0 & 0 \\
\hline Cukup & 0 & 0 \\
\hline Baik & 41 & 100 \\
\hline Total & $\mathbf{4 1}$ & $\mathbf{1 0 0}$
\end{tabular}

Berdasarkan tabel 2 menunjukkan bawah responden setelah diberikan pendidikan kesehatan dengan media leaflet memiliki tingkat pengetahuan baik sebanyak 41 orang (100\%).

Pengaruh Pendidikan
terhadap pesehatan
mengahadapi bencana banjir.

Tabel 3 Tabulasi Silang Pengaruh Pendidikan Kesehatan terhadap pengetahuan dalam mengahadapi bencana banjir.

\begin{tabular}{lll}
\hline $\begin{array}{r}\text { Pendidikan } \\
\text { Keseha } \\
\text { tan } \\
\begin{array}{l}\text { Penge } \\
\text { tahuan }\end{array}\end{array}$ & Sebelum & Sesudah \\
\hline Baik & $36(87,8 \%)$ & $41(100 \%)$ \\
\hline Cukup & $2(4,9 \%)$ & $0(0 \%)$
\end{tabular}

\begin{tabular}{ccc}
\hline Kurang & $3(7,3 \%)$ & $0(0 \%)$ \\
\hline & $\begin{array}{c}\text { Hasil Uji Wilcoxon } \mathrm{P}=0.038 \\
\text { menunjukkan } \alpha<0,05\end{array}$ \\
\hline
\end{tabular}

Dapat diketahui bahwa sebagian besar responden sebelum dilakukan penyuluhan didapatkan tingkat pengetahuan yang kurang sebanyak 3 (7,3\%), pengetahuan cukup sebanyak 2 $(4,9 \%)$ serta pengetahuan baik sebanyak 36 (87,8\%). Sedangkan setelah dilakukan penyuluhan yang mengalami kenaikan untuk pengetahuan baik menjadi 41 orang $(100 \%)$.

Hasil analisis dengan menggunakan uji statistic berdasarkan data sebelum dan sesudah diberikan penyuluhan dianalisa menggunakan uji Wilcoxon dengan derajat kemaknaan $\mathrm{p}<0,005$ maka $\mathrm{H}_{0}$ ditolak, maka ada pengauruh pendidikan kesehatan dengan media leaflet terhadap tingkat pengetahuan tentang kesiapsiagaan bencana di wilayah Petemon RT 008 / RT 009 Surabaya. 


\section{PEMBAHASAN}

\section{Tingkat pengetahuan tentang kesiapsiagaan bencana banjir sebelum diberikan pendidikan kesehatan}

Berdasarkan tabel 1 menunjukkan bahwa sebagian besar responden sebelum diberikan pendidikan kesehatan didapatkan bahwa semua responden di Petemon Surabaya mengalami kualitas tingkat pengetahuan baik yaitu 36 orang $(87,78 \%)$. Menurut Santrock J.W,(2018) Semakin bertambahnya usia, maka sesorang dapat menerima informasi dan pengalaman yang banyak, sehingga dapat meningkatkan pengetahuan dengan mendapatkan pengalaman yang banyak dan akan menambah tingkatan pengetahuan atau wawasan seseorang dalam sikapnya bertindak. Menurut Hurlock (2015) Usia yang memiliki individu juga memiliki pengaruh yang cukup signifikan terhadap perilaku individu, bahwa usia seseorang akan mempengaruhi kemampuan untuk berinteraksi dan bersosialisasi dengan orang lain disekitarnya. Berdasarkan data usia masyarakat yaitu 20-35 tahun 23 orang $(56,09 \%)$ dan usia $36-50$ sebanyak 18 orang $(43,90 \%)$. Berdasarkan jenis kelamin diketahui mayoritas masyarakat berjenis kelamin perempuan sebanyak 25 orang $(60,97 \%)$ dan selebihnya responden yang berjenis laki - laki 16 orang (39,02\%). Menurut Suwarjo (2013). Perempuan sering terlihat dikegiatan sosial sehingga memiliki tanggung jawab dalam mengatasi bencan banjir, tentang faktor-faktor yang mempengaruhi tingkat pengetahuan masyarakat dalam mitigasi bencana alam bahwa perempuan memliki pengetahuan yang lebih unggul mengenai mitigasi bencana. Berdasarkan hasil penelitihan dapat dilihat bahwa karakteristik responden berdasarkan jenis kelamin didominasi perempuan dikarenakan bahwa perempuan mempunyai tanggung jawab dan kecerdasan. Hal ini mendukung hasil penelitian yang telah diperoleh.

Berdasarkan tingkat pendidikan dapat diketahui jumlah responden dengan pendidikan SD berjumlah 2 orang $(4,87 \%)$, SMP berjumlah 7 orang $(17,07 \%)$, SMA berjumlah 18 orang $(43,90 \%)$ dan diploma / sarjana berjumlah 14 orang $(34,14 \%)$. Menurut Mubarak (2013), bahwa semakin tinggi pendidikan seseorang tersebut untuk menerima informasi dan semakin banyak pula pengetahuan yang dimilikinya. Sehingga semakin mudah untuk menerima tingkat pengetahuan terkait masyarakat dalam menghadapi bencan banjir. Sedangkan sebaliknya masyarakat yang berpendidikan rendah cenderung kurang mengetahui informasi sehingga mempengaruhi pengetahuan dalam hal tingkat pengetahuan. Masyarakat belum memliki kesiapan dan langkah-langkah yang harus dilakukan sebelum, sesaat, dan setelah banjir. Masyarakat perlu diberikan pendidikan dan pelatihan kesiapsigaan dalam menghadapai banjir. Hal ini sejalan dengan hasil penelitian dimana mayoritas responden memiliki pengetahuan baik dengan tindakn Pendidikan mayoritas SMA.

\section{Tingkat pengetahuan tentang kesiapsiagaan bencana banjir setelah diberikan pendidikan kesehatan}

Berdasarkan tabel 2 menunjukkan bahwa sebagian besar responden setelah diberikan Penyuluhan didapatkan bahwa responden di 
Petemon Gang 2 RT008/RT009 Surabaya mengalami kenaikan tingkat pengetahuan baik menjadi 41 orang (100\%). Hal tersebut menunjukkan bahwa terjadi peningkatan kualitas tingkat pengetahuan pada masyarakat setelah diberikan penyuluhan. Untuk menanggulangi masalah banjir yang ada perlu dilakukan suatu pendidikan edukasi berupa pengetahuan, pemahaman, kesiapsiagaan dan keterampilan untuk mencegah, mendeteksi, dan mengantisipasi secara lebih dini tentang berbagai macam bencana khususnya di daerah-daerah rawan bencana. Bila sesorang memiliki pengetahuan secara menyuluruh dari semua bahan yang telah dipelajarinya. Bahkan melalui kriteria yang telah ditentukan, mampu mengavaluasi semua yang telah dikerjakan. Pengetahuan empiris tersebut juga dapat berkembang menjadi pengetahuan deskriptif bila seseorang dapat melukiskan dan menggambarkan segala ciri,sifat, dan gejala yang ada pada obyek empiris tersebut. Pengetahuan empiris juga bisa didapatkan melalui pengalaman pribadi manusia yang terjadi mengalami banjir dengan sendirinya akan mendapatkan pengetahuan bagaimana mengatasi masalah banjir dan bertindak untuk melakukan penanggulangan atau bahkan meningkatkan kesiapsiagaan dalam menghadapi banjir.

Penelitian ini sejalan dengan penelitih Ali, Mohamad 2018. Masyarakat lebih mengetahui bencana banjir, karena bencana merupakan bencana umum bagi masyarakat setempat. Masyarakat sudah mengetahui cara mencegah dan mengurangi dampak bencana banjir disetiap keluruhan.

\section{Pengaruh pendidikan kesehatan terhadap Tingkat pengetahuan tentang kesiapsiagaan bencana banjir}

Pada tabel 3 dapat dilihat bahwa semua responden sebelum diberikan pendidikan mengalami tingkat pengetahuan baik sebanyak 36 orang $(87.8 \%)$ sedangkan setelah diberikan pendidikan kesehatan tingkat pengetahuan yang baik menjadi 41 orang $(100 \%)$. Hasil dari uji stastistik wilcoxon didapatkan tingkat signifikan sebesar $\mathrm{P}=0,038$ dimana $\alpha<0,05$ yang menujukkan bahwa H1 diterima, dimana kesimpulannya bawah ada kualitas tingkat pengetahuan masyarakat di Petemon Surabaya.

Penelitian ini sejalan dengan penelitian dari Notoatmodjo, 2017. Faktor yang mempengaruhi pengetahuan adalah usia karena usia mempengaruhi daya tangkap dan pola pikir sesorang. Ketika seseorang bertambah usia akan menurun pula daya tangkap dan pola pikirnya serta faktor lingkungan karena segala sesuatu yang ada di sekitar individu,baik lingkungan fisik,biologi, maupun sosial. Lingkungan berpengaruh terhadap proses masuknya pengetahuan.

Dari hasil penelitian ini menujukkan uji wilcoxon dengan meggunakan uji $\alpha<0,005$, yang berarti ada pengaruh pendidikan kesahatan terhadap pengetahuan kesiapsigaan masyrakat dalam menghadapai bencan banjir di daerah petemon surabaya.

Berdasarkan hasil penelitian serta teori yang ada maka dapat disimpulkan bahwa ada pengaruh sebelum dan setelah dilakukan pendidikan kesehatan terhadap pengetahuan masyarakat dalam kesiapsiagaan bencan banjir. Dalam penilitian ini pemberian pendidikan kesehatan ini menggunakan media leaflet. Metode media leaflet dapat membantu masyrakat untuk meningkatkan perilaku kesiapsigaan masyarakat, memahami dan menerapkan isi atau informasi yang 
diberikan saat dilakukan pendidikan kesehatan .

\section{SIMPULAN DAN SARAN}

Berdasarkan hasil penelitian dapat disimpulkan bahwa Terdapat pengaruh pendidikan kesehatan dengan media leaflet terhadap tingkat pengetahuan masyarakat tentang kesiapsiagaan bencana banjir di Petemon Surabaya dibuktikan dengan hasil uji Wilcoxon $p=0,038$

Berdasarkan kesimpulan di atas, diharapkan penelitian ini menjadi dasar bagi peneliti selanjutnya untuk melakukan penelitian dapat dikembangkan dengan penelitian yang sama dengan populasi yang lebih representative untuk mendukung program pemerintah.

\section{DAFTAR PUSTAKA}

Adi S. (2014). Karakterisasi Bencana Banjir Bandang Di Indonesia. Jurnal Sains dan Teknologi Indonesia 15 (1), 45

Ali, Mohamad 2018. Penlitian kependidikan Prosedur dan Strategi. Bandung : Angkasa

Arikunto, Suhasimi (2017). Prosedur Penelitian Suatu Pendekatan Praktis, Jakarta : Rineka Ciptia.

BNPB(2017)'PengetahuanKebencana an', in BNPB. Jakarta: www.bnpb.go.id.

Husna, C. (2012) 'Influencing Factors on Disaster Preparedness in RSUDZA Banda Aceh Cut Husna', Idea Nursing Journal, 3(2).

Gumilar, I. (2013): Pemetaan Karakteristik Penurunan Muka Tanah (Land Subsidence) Berdasarkan Pengamatan Metode
Geodetik Serta Estimasi Kerugian Ekonomi Akibat Dampak Penurunan Muka Tanah (Wilayah Studi: Cekungan Bandung). Disertasi Program Doktor. Institut Teknologi Bandung.

Hurlock Elizabet, 2015, Psikologi Perkembangan Suatu Pendekatan Rentang Hidup Jakarta: Erlangga.

Marfai, MA, Mardianto, D., Cahyadi, A.,Nucifera, F.,dan Prihatno, H. (2013). Pemodelan Spasial Bahaya Banjir Rob berdasarkan Skenario Perubahan Iklim dan Dampaknya di Pesisir Pekalongan. Jurnal Bumi Lestari, volume 13, No. 2

Mulyanto,HR,dkk.2012.Pentunjuk Tindakan dan Sistem Mitigasi Bencana. Jakarta: JICA

Mubarak 2013. Pendidikan Kesehatan, Jakarta :EGC

Nursalam (2016). Konsep dan Penerapan Metodologi Penelitian Ilmu Keperawatan : Pedoman Skripisi, Tesis dan Instrumen Penelitian Keerawatan. Jakarta: Salemba Medika.

Notoatmodjo, S. (2007) Promosi Kesehatan dan Ilmu Perilaku. Jakarta: Rineka Cipta.

Paripurno, Eko Teguh.2013.Manajemen Resiko Bencana : Alternatif dari bawah. Jurnal Dialog Kebijakan. Publik. Edisi 1 juni

Rahayu, dkk. (2009). Banjir dan Upaya Penanggulangannya. Bandung: Pusat Mitigasi Bencana (PMBITB). 
Ristika Pramadita Rosa, Irma Prasetyowati, Ni'mal Baroya. 2013. Peta Spasial Indeks Rawan Bencana Banjir Jawa Timur Menggunakan Sistem Informasi Geografis (SIG). http://repository.unej.ac.id/bitstrea $\underline{\mathrm{m} / \text { handle/123456789/61857/Ristik }}$ a\%20Pramadita\%20Rosa.pdf?seq $\underline{\text { uence }}=1$

Ruswandi, D. (2014). Indeks Resiko Bencana Indonesia. Direktorat Pengurangan Risiko Bencana Deputi Bidang Pencegahan dan Kesiapsiagaan : Indonesia

Santrock, J.W. (2018). Life-Span Development (Perkembangan Masa Hidup Edisi 13 Jilid 1, Penerjemahan: Widyasinta.B). Jakarta : Erlangga

Sedarmayanti dan Syarifudin Hidayat. 2017. Metodologi Penelitian. Bandung: Mandar Maju

Setiadi,2014. Konsep dan Promosi Keperawatan. Yogyakarta: Salemba.

Susilo.R.2011. Pendidikam Kesehatan Dalam Keperawatan. Muha Medika. Yogyakarta.

Suwarjo, Arusma, L.S. 2013. Manajemen Bimbingan dan Konseling di SMAN 4 Yogyakarta : Jurnal Akuntabilitas Manajemen Pendidikan Vol. 1

UU RI No.24 (2007) Undang-Undang RI Nomor 24 Tahun 2007 Tantang Penanggulangan Bencana

Yulaelawati.2018. Mencerdasi Bencana . Surakarta: PT.Grasindo 